\title{
UM ESTUDO SOBRE OS IMPACTOS DA NOTA FISCAL ELETRÔNICA PARA PEQUENAS E MÉDIAS EMPRFESAS DO RAMO ODONTOLÓGICO
}

\section{A STUDY ABOUT THE IMPACT FROM THE ELECTRONIC RECEIPT FOR SMALL AND MEDIUM ENTERPRISES IN ODONTOLOGICAL SECTOR}

\author{
Dulce Aparecida Correia \\ Especialista em Finanças e Banking \\ Universidade Nove de Julho, São Paulo, Brasil \\ Osmildo Sobral dos Santos \\ Doutorado em Engenharia de Produção Universidade Paulista \\ UNIP, Brasil
}

\section{RESUMO}

Este artigo pretende abordar alguns impactos relacionados à implantação do projeto de lei que obriga a emissão da Nota Fiscal Eletrônica para as empresas que antes emitiam Nota Fiscal em papel (talonário). Devido ao grande volume de documentos em papel que circulam e são armazenados, tanto pela administração tributária como pelos contribuintes, é substancialmente elevado, portanto, a integração e compartilhamento de informações têm o objetivo de racionalizar e modernizar a administração tributária brasileira, reduzindo custos e entraves burocráticos, facilita o cumprimento das obrigações tributárias e o pagamento de impostos e contribuições, além de fortalecer o controle e a fiscalização por meio de intercâmbio de informações. De modo geral, o projeto governamental justifica-se pela necessidade de investimento público voltado para a redução da burocracia do comércio e dos entraves administrativos enfrentados pelos empresários do País, exige da modernização das administrações tributária. Este projeto prevê ainda o investimento em tecnologia de forma a modernizar sistemas de informação, ampliando a capacidade de atendimento das unidades administrativas. Neste estudo foram analisados os impactos da NF-e para as pequenas e médias empresas do ramo odontológico, abordando a carga tributária no Brasil, os principais tributos existentes, e a Agencia Nacional de saúde (ANS) via questionário.

Palavras-chave: NF-e, pequenas e médias empresas, impostos.

\section{ABSTRACT}

This article intends to approach some impacts related to the bill that requires the issuance of Electronic Receipt for enterprises which used to emitted receipt paper (checkbook). Due to the large amount of documents paper circulating and stored by both the tributary administration and the taxpayers is substantially high, therefore integrating and sharing information are intended to streamline and modernize the Brazilian tax administration, 
reducing costs and paperwork obstacles, makes it easy the fulfillment of the tax liability and the tax payment and contributions, as well as strengthening the controlling and monitoring by information exchange. Generally speaking, the government project is justified by the necessity of public investment to the reduced paperwork and administrative trade barriers faced by businessmen in the country, requiring the modernization of tributary administrations. This project also predicts investment in technology to upgrade the information systems, expanding the service capacity of administrative units. This present study analyzed the impacts of receipt for small and medium enterprises in odontological sector approaching the tax burden in Brazil, the main existing taxes, and the National Health Agency (NHA) by questionnaire.

Keywords: NF-e, small and medium enterprises, impost. 


\section{INTRODUÇÃO}

Conforme o Portal da Secretaria da Receita Federal do Estado de São Paulo (2011), para atender o disposto da Emenda Constitucional $\mathrm{n}^{\circ} 42$, Inciso XXII, art. 37, foi realizado, nos dias 15 a 17 de julho de 2004, em Salvador, o $1^{\circ}$ Encontro Nacional de Administradores Tributários - ENAT, reunindo os titulares das administrações tributárias federal, estaduais, do Distrito Federal e dos municípios de capitais.

O encontro teve como objetivo buscar soluções conjuntas das três esferas de Governo que promovessem maior integração administrativa, padronização e melhor qualidade das informações, racionalização de custos e da carga de trabalho operacional, fiscalização; maior possibilidade de realização de ações fiscais coordenadas e integradas; maior possibilidade de intercâmbio de informações fiscais entre as diversas esferas governamentais; cruzamento de dados em larga escala com dados padronizados e uniformização de procedimentos.

Comenta ainda o Portal da Receita Federal do Estado de São Paulo (2011), que o ENAT (Encontro Nacional de Administradores Tributário) foi aprovado dois protocolos de cooperação técnica nas áreas do cadastramento (Projeto do Cadastro Sincronizado) e Nota Fiscal Eletrônica, visando alinhar as diretrizes do projeto, iniciado pelo ENAT, com o fórum de discussão dos Coordenadores e Administradores Tributários Estaduais (ENCAT), foi realizado uma Reunião Técnica do ENAT/ENCAT, em São Paulo-SP, em 27 de abril de 2005, para a unificação dos diferentes projetos em andamento no âmbito das Administrações Tributárias. No final de agosto/2005, no evento do II ENAT - Encontro Nacional de Administradores Tributários, em São Paulo, os Secretários de Fazenda dos Estados e DF, o Secretário da Receita Federal e os representantes das Secretarias de Finanças dos municípios das Capitais assinaram o Protocolo ENAT 03/2005, visando o desenvolvimento e a implantação da Nota Fiscal Eletrônica, consolidando de forma definitiva a coordenação técnica e o desenvolvimento do projeto sob a responsabilidade do ENCAT (Encontro Nacional dos Coordenadores e Administradores Tributários Estaduais) com a participação, da agora denominada, Receita Federal do Brasil (RFB).

Na continuidade dos estudos o Portal da Secretaria da Receita Federal do Estado de São Paulo (2011), partir de novembro de 2005 a Superintendência da Zona Franca de Manaus (Suframa) passou a integrar o projeto, visando a possibilitar uma adaptação gradativa dos contribuintes e da sociedade a este novo modelo, a NF-e está sendo implantada em duas etapas:

$1^{\text {a }}$ Fase - Piloto (Fase Pré-operacional) - a primeira fase de implantação do projeto ocorre desde abril de 2006 com 19 (dezenove) empresas voluntárias autorizadas por seis Secretarias de Fazenda (BA, SP, RS, SC, GO e MA). As NF-e têm sido emitidas de forma simultânea às suas tradicionais notas fiscais em papel, modelo 1 e $1 \mathrm{~A}$.

Nesta fase, as NF-e e os respectivos DANFES não têm validade tributária.

$2^{\mathrm{a}}$ fase (Operacional), em 15/09/06 iniciou-se a fase operacional em que as NF-e passaram a ter validade jurídica. Desde dezembro/2006 a SEFAZ/SP credenciou 50 novas empresas voluntárias como emissoras de NF-e. $3^{\text {a }}$ fase (Massificação), a partir da publicação da Portaria CAT 104/07, as empresas podem credenciar-se como 
emissoras de NF-e. Segundo o Portal da Secretaria da Fazenda do Estado de São Paulo (2011), o Projeto NF-e tem como objetivo a implantação de um modelo nacional de documento fiscal eletrônico que venha substituir a sistemática atual de emissão do documento fiscal

em papel, com validade jurídica garantida pela assinatura digital do remetente, simplificando as obrigações acessórias dos contribuintes e permitindo, ao mesmo tempo, acompanhamento em tempo real das operações comerciais pelo Fisco.

A implantação da NF-e constitui grande avanço para facilitar a vida do contribuinte e as atividades de fiscalização sobre operações e prestações tributadas pelo Imposto sobre Circulação de Mercadorias e Serviços (ICMS) e pelo Imposto sobre Produtos Industrializados (IPI). Num momento inicial, a NF-e será emitida apenas por grandes contribuintes e substituirá os modelos, em papel, tipo 1e 1A.

Na continuidade dos estudos o Portal da Secretaria da Fazenda do estado de São Paulo (2011) diz que, a busca pela integração e modernização da Administração Tributária relaciona-se à forma federativa adotada pelo estado brasileiro. Neste contexto, a União, os Estados, o Distrito Federal e os Municípios são dotados de autonomia política, administrativa e financeira, estando suas atribuições, limitações e competências previstas na Constituição Federal, que concede a cada esfera de governo a competência de instituir e administrar os respectivos tributos.

A integração e cooperação entre administrações tributárias têm sido temas muito debatidos em países federativos, especialmente naqueles que, como o Brasil, possui forte grau de descentralização fiscal. Nesses países, a autonomia tributária tem gerado, tradicionalmente, multiplicidade de rotinas de trabalho, burocracia, baixa grau de troca de informações e falta de compatibilidade entre os dados econômico-fiscais dos contribuintes. Para os cidadãos, o Estado mostra-se multifacetado, ineficiente e moroso.

Conforme a Receita Federal do Estado de São Paulo (2011), o governo, o controle apresenta-se difícil porque falta à visão integrada das ações dos contribuintes. Para o País, o custo público e privado do cumprimento das obrigações tributárias tornase alto, criando um claro empecilho ao investimento e geração de empregos. Com o advento da sociedade da informação os agentes econômicos aumentaram a sua mobilidade, exercendo ações em todo o território nacional e deixa de estar restritos ao conceito de jurisdição territorial. Em decorrência, é comum que empresas sejam contribuintes, simultaneamente, de diversos governos, em nível federal, estadual ou municipal.

A consequiência direta deste modelo é que os bons contribuintes acabam penalizados pela burocracia, pois têm que lidar com procedimentos e normas diversos em cada unidade da federação ou município.

As administrações tributárias enfrentam o grande desafio de adaptarem-se aos processos de globalização e de digitalização do comércio e das transações entre contribuintes.

Ainda conforme Receita Federal do Estado de São Paulo (2011), os volumes de transações efetuadas e os montantes de recursos movimentados crescem num ritmo intenso e, na mesma proporção, aumentam os custos inerentes à necessidade do Estado de detectar e prevenir a evasão tributária. No que se refere às administrações tributárias, há a necessidade de despender grandes somas de recursos para captar, tratar, armazenar e disponibilizar informações sobre as operações realizadas pelos contribuintes, administrando um volume de obrigações acessórias que acompanha 
o surgimento de novas hipóteses de evasão, no que tange aos contribuintes, há a necessidade de alocar recursos humanos e materiais vultosos para o registro, contabilidade, armazenamento, auditoria interna e prestação de informações às diferentes esferas de governo que, no cumprimento das suas atribuições legais, as demandam, usualmente por intermédio de declarações e outras obrigações acessórias. Indubitavelmente, o custo inerente ao grande

volume de documentos em papel que circulam e são armazenados, tanto pela administração tributária como pelos contribuintes, é substancialmente elevado, portanto a integração e compartilhamento de informações têm o objetivo de racionalizar e modernizar a administração tributária brasileira, reduzindo custos e entraves burocráticos, facilitando o cumprimento das obrigações tributárias e o pagamento de impostos e contribuições, além de fortalecer o controle e a fiscalização por meio de intercâmbio de informações entre as administrações tributárias.

Consta ainda no Portal da Receita Federal do Estado de São Paulo (2011), que, para atender a estas necessidades, a Emenda Constitucional $n^{\circ} 42$ introduziu o Inciso XXII ao art. 37 da Constituição Federal, que determina às administrações tributárias da União, dos Estados, do Distrito Federal e dos Municípios a atuar de forma integrada, inclusive com o compartilhamento de cadastros e de informações fiscais, de modo geral, o projeto justifica-se pela necessidade de investimento público voltado para a redução da burocracia do comércio e dos entraves administrativos enfrentados pelos empresários do País, exigindo a modernização das administrações tributária nas três esferas de governo, esse projeto prevê ainda o investimento em tecnologia de forma a modernizar os sistemas de informação, ampliando a capacidade de atendimento das unidades administrativas.

\section{FUNDAMENTAÇÃO TEÓRICA}

Conforme a Receita Federal do Estado de São Paulo (2011) na 119a reunião ordinária do Conselho Nacional de Política Fazendária, realizada em Manaus, AM, no dia 30 de setembro de 2005, a Nota Fiscal Eletrônica foi criada com a finalidade de alterar o sistema atual de emissão da nota fiscal em papel Modelo 1 ou $1 \mathrm{~A}$, por nota fiscal eletrônica com validade jurídica para todos os fins. Conforme a Secretaria da Fazenda, o conceito adotado trata a Nota Fiscal Eletrônica como um documento de existência apenas digital, emitido e armazenado eletronicamente, com o intuito de documentar, para fins fiscais, uma operação de circulação de mercadorias ou uma prestação serviços, ocorrida entre as partes, e cuja validade jurídica é garantida pela assinatura digital do emissor (garantia de autoria e de integridade) e pela recepção, pela Fazenda, do documento eletrônico, antes da ocorrência da circulação ou saída da mercadoria e/ou prestação de serviços ocorrida entre as partes, cuja validade jurídica é garantida pela assinatura digital do emitente e recepção, pelo fisco, antes da ocorrência do Fato Gerador.

\section{1 - EMISSÃO DA NOTA FISCAL ELETRÔNICA}

No Portal da Secretaria da Fazenda Estado de São Paulo (2011), tem todos os passos para emitir a NF-e, e o software é disponibilizado pela no site da própria secretaria. 
Para se gerar a NF-e precisa ter acesso a um computador razoável, acesso á internet e banda larga, e possuir um certificado digital que é um documento eletrônico usado para identificar as duas partes de uma transação online, e além uma boa organização interna, com lista de produtos, critérios para identificação de produtos, listas de transações fiscais e seu uso correto uso, controle sobre os documentos já impressos e boa sintonização com seu serviço de contabilidade, através de um código emitido em tempo real pela Secretaria da Fazenda, o empresário poderá dar início ao transporte da mercadoria. Para assegurar a rápida liberação nos postos de fiscalização de mercadoria em trânsito, será emitido um documento denominado de DANFE - Documento Auxiliar da Nota Fiscal Eletrônica, que terá como principal finalidade acompanhar a mercadoria e, considerando que carregará o código que liberou a emissão da NF-e, servirá de documento hábil para consultas pela administração tributária.

Ainda, no Portal da Secretaria da Fazenda do Estado de São Paulo (2011), o sistema de credenciamento para emissão de NF-e no estado de São Paulo está disponível no site www.fazenda.sp.gov.br/nfe opção credenciamento, o acesso ao sistema é efetuado por meio do mesmo usuário e senha de contribuinte utilizado para acessar os serviços do Posto Fiscal Eletrônico - PFE, ao acessar o sistema, selecione um estabelecimento e informe os dados dos contatos da empresa responsáveis pela Nota Fiscal Eletrônica, as informações, o estabelecimento já estará autorizado, automaticamente, a iniciar os testes de sua solução tecnológica de emissão de NF-e no ambiente de teste/homologação da SEFAZ-SP.

Os testes realizados neste ambiente não serão avaliados pela SEFAZ-SP, apesar dos testes no ambiente de testes/homologação da SEFAZ-SP não serem obrigatórios, é recomendado que o contribuinte efetuasse seus testes antes de solicitar seu credenciamento no ambiente de produção. Para entrar em produção, após a realização de todos os testes que julgar necessário, clique no botão "Credenciamento para emitir NF-e em produção"; Ao credenciar-se no ambiente de produção, o estabelecimento continuará a ter acesso ao ambiente de testes da SEFAZSP para realizar os testes que julgar necessário.

Dentre os benefícios do emprego desta nova Sistemática, que poderá ser observados, a redução no tempo de parada nas fronteiras, e no custo pela dispensa de emissão e armazenamento das Notas Fiscais, maior comprometimento em tempo real de informações entre o Fisco e o Contribuinte e também diminuição desleal na concorrência promovida pelos sonegadores.

Pioneiramente a Prefeitura do Estado de São Paulo, instituiu que casa prestação transacionada com a NF-e acumulará créditos que poderão ser utilizados para abater 50\% do IPTU - Imposto Sobre Propriedade Territorial Urbana, devido por pessoas físicas ou jurídicas. É oportuno verificar-se que a modernidade e a velocidade desses novos controles resultarão numa maior arrecadação, com o crescimento do volume de tributos

arrecadados, impulsionado principalmente pela regulamentação de novas empresas, o que poderão sinalizar uma nova esperança para a redução da carga tributária.

\section{2 - CIRCULAÇÃO DE MERCADORIAS E SERVIÇOS}

Segundo Borges (2009), o ICMS (imposto sobre operações relativas á 
circulação de mercadoria e sobre prestação de Serviços de transporte Interestadual, intermunicipal e de comunicação, é de competência dos Estados e do Distrito Federal), sua regulamentação constitucional está prevista na lei Complementar 87/1996, posteriormente alterada pelas leis Complementares 92/97, 99/99 e 102/2000.

$\mathrm{O}$ fato gerador é a circulação de mercadorias, a prestação de serviços de comunicação, alíquota de ICMS tem limites fixados pelo Senado Federal e suas reduções são condicionadas á aprovação de tosos os Estados mediante ao convênio que varia conforme as regiões do país de acordo com a natureza do produto e que o ICMS é o mais importante imposto estadual, porque representa a mais expressiva fonte de receita tributária e pode a chegar a 90\% do total arrecadado.

Arrecadação do ICMS é controlada por meio de documentos fiscais. Existem diversas modalidades de documentos fiscais que o mais conhecido são a Nota Fiscal de Venda ao Consumidor e o cupom fiscal.

Explana no Portal da Secretaria da Receita Federal do Estado de São Paulo (2011), a implantação da Nota Fiscal Eletrônica (NF-e) tem o objetivo de facilitar a vida do contribuinte e as atividades de fiscalização sobre operações e prestações tributadas pelo Imposto sobre Circulação de Mercadorias e Serviços (ICMS) e pelo Imposto sobre Produtos Industrializados (IPI). Os estabelecimentos estão implantando o documento fiscal eletrônico e, assim, substituindo a emissão do documento fiscal em papel. Para isso, é necessário obter certificado digital padrão ICPBrasil para garantir validade jurídica na assinatura e transmissão do documento eletrônico, até a obrigatoriedade de setembro de 2009, a legislação não vinculou a obrigatoriedade de emissão de NF-e com nenhum código CNAE (Classificação Nacional de Atividades Econômicas), específico em que o contribuinte esteja cadastrado junto aos órgãos públicos. O contribuinte estará obrigado à emissão de NFe.

Portal da Secretaria da Receita Federal do Estado de São Paulo (2011), diz que a partir de 2010, a obrigatoriedade é definida por CNAE principal ou secundário, conforme conste ou, por exercer a atividade, deva constar dos atos constitutivos ou dos cadastros do contribuinte junto ao CNPJ ou SEFAZ, para os contribuintes não abrangidos pelo Anexo I da Portaria CAT 162/2008. Clique aqui para consultar a obrigatoriedade para 2010. Clique aqui para consultar a obrigatoriedade para 2011, com a Nota Fiscal eletrônica a sonegação do ICMS será mais difícil, porque irão se cruzar as informações junto a Receita Federal, o Fisco, etc.

\section{3 - SISTEMA TRIBUTÁRIO NACIONAL}

Na percepção de Becker (2007), o sistema tributário brasileiro passou por profunda reforma na década de 60 . Desde então, a reforma realizada no âmbito da

Assembleia Nacional Constituinte, em 1987/88, o sistema evoluiu continuamente, sem alterações em sua estrutura básica. Embora a Constituição de 1988 tenha eliminado alguns tributos e introduzido modificações nas características de outros, notadamente do principal tributo estadual, a reforma de então teve como principal motivação a desconcentração dos recursos públicos, privilegiando especialmente os municípios.

Desse modo, a estrutura básica da tributação brasileira vigente ainda é, em 
essência, aquela construída em 1964/67.

Becker (2007) comenta que, a primeira das motivações usuais para a reforma é o aprimoramento dos tributos no que diz respeito a seus efeitos sobre o sistema produtivo.

Salvo nos casos em que os tributos são utilizados como instrumentos de política para,intencionalmente, alterar o comportamento dos agentes econômicos, é desejável que sejam neutros, ou seja, que não afetem suas decisões. Na prática, não há tributos neutros, sendo objetivo típico da política tributária em minimizar os malefícios por eles causados à eficiência da economia e à competitividade do setor produtivo.

A segunda motivação é a questão da equidade. Deseja-se que a tributação seja justa, e tenha um impacto favorável sobre a distribuição de renda. É duvidoso, contudo, que, em um mundo de intensa mobilidade do capital, a tributação possa ter impacto redistributivo significativo. Se esse for, de fato, o caso, um objetivo mais modesto se impõe, qual seja o de assegurar, ao menos, que ela não seja regressiva, isto é, que não onere relativamente mais os pobres que os ricos. Isto assegurado é possível, com os recursos arrecadados, financiar políticas governamentais bem concebidas, focalizadas e executadas, que beneficiem principalmente os mais pobres, assegurando o cumprimento do papel redistributivo do governo, o que é especialmente importante em um contexto de globalização economicamente.

\section{4 - CLASSIFICAÇÕES DOS TRIBUTOS}

Segundo Pereira (2011), entende-se toda prestação pecuniária compulsória em moeda ou cujo valor nela se possa exprimir, que não constitua sanção de ato ilícito, instituída em lei e cobrada mediante atividade administrativa plenamente vinculada - art. $3^{\circ}$ do Código Tributário Nacional - CTN, nos termos do artigo 145 da nossa Constituição Federal e do artigo $5^{\circ}$ do CTN, tributos são:

- Impostos.

- Taxas, cobradas em razão do exercício do poder de policia ou Pela utilização,efetiva ou potencial, de serviços públicos.

- Contribuição de melhoria, decorrente de obras públicas.

Pereira (2011) comenta que juridicamente, no Brasil, hoje, entende-se que as contribuições para fiscais ou especiais integram o sistema tributário nacional, já que a nossa Constituição Federal ressalva quanto á exigibilidade da contribuição sindical (art. 80, inciso IV, CF), das contribuições previdenciárias (artigo $201 \mathrm{CF}$ ), sociais (artigo $149 \mathrm{CF}$ ). Para a seguridade social (artigo $195 \mathrm{CF}$ ) e para o PIS Programa de Integração

Social e PASEP — Programa de Formação do Patrimônio do Servidor Público (artigo $239 \mathrm{CF}$ ).

Becker, (2007), classifica ainda os tributos como:

- Diretos - são quando numa só pessoa reúnem-se as condições de contribuinte (aquele que é responsável pelo cumprimento de todas as obrigações tributárias previstas na legislação). Exemplo: Imposto de Renda por declaração.

- Indiretos - é quando na relação jurídico-tributária que se estabelece entre o Estado e o sujeito passivo, este paga o tributo correspondente e se ressarce cobrando de terceiro através da inclusão do imposto no preço. Exemplos: IPI e ICMS. 
- Reais - São aqueles que não levam em consideração as condições do contribuinte, indicando igualmente a todas as pessoas. Exemplo: IPTU.

- Pessoais - São aqueles que estabelecem diferenças tributárias em função das condições próprias do contribuinte. Exemplo: Imposto de Renda das Pessoas Físicas e Pessoas

- Jurídicas. Proporcionais - São caracterizados quando os impostos são estabelecidos em percentagem única incidente sobre o valor da matéria tributável. Exemplo: ITBI.

- Progressivos - São os impostos cujas alíquotas são fixadas em percentagens variáveis e crescentes. Exemplo: Imposto de Renda - Pessoa Física.

- Fixos - é quando o valor do imposto é determinado em garantia certa, independendo de cálculo. Exemplo: ISS - enquadramento por estimativa anual.

- Fiscais - criado para arrecadar recursos à pessoa jurídica de direito público interno, para que possa cobrir seus gastos. Exemplo: Imposto de Renda.

- Para fiscais - contribuição cobrada por autarquia, profissionais ou sociais, para custear financiamento autônomo. Exemplo: taxa anual do CRC, CREA, etc.

- Extra Fiscais - quando não visa só à arrecadação, mas também, corrigir anomalias. Exemplo: Imposto de Exportação.

\section{5 - FORMAS DE TRIBUTAÇÃO}

Becker (2007), explica que as formas de tributação existente no Brasil para Pessoas Jurídicas, por opção ou por determinação legal, são tributadas por uma das seguintes formas: Simples Nacional, Lucro Presumido, Lucro Real e Lucro Arbitrado.

Simples Nacional - A Lei Complementar $n^{\circ}$ 123/2006, instituiu, a partir de 01.07.2007, novo tratamento tributário simplificado, também conhecido como Simples Nacional ou Super Simples. O Simples Nacional estabelece normas gerais relativas ao tratamento tributário diferenciado e favorecido a ser dispensado às microempresas e empresas de pequeno porte no âmbito da União, dos Estados, do Distrito Federal e dos Municípios, mediante regime único de arrecadação, inclusive obrigações acessórias.

Esse Regime substituiu, a partir de 01.07.2007, o Simples Federal (Lei 9.317/1996), que foi revogado a par/ir daquela data. A unificação de impostos é a

principal vantagem do Simples. Veja quais impostos são unificados: Federais: Imposto sobre a Renda da Pessoa Jurídica (IRPJ); Contribuição Social sobre o Lucro Líquido (CSLL); Contribuição para o PIS/Pasep; Contribuição para o Financiamento da Seguridade Social (COFINS); Imposto sobre Produtos Industrializados (IPI). As alíquotas variam de $4 \%$ a $12 \%$ de acordo com a categoria em que a empresa está inserida.

Lucro Real - A expressão Lucro Real significa o próprio lucro tributável, para fins da legislação do imposto de renda, ou seja, o resultado contábil ajustado pelas adições, exclusões ou compensações previstas na legislação para ser tributado, distinto do lucro líquido apurado contabilmente.

Como regra as empresas apuram o imposto de renda devido em períodos trimestral, encerrados em 31 de março, 30 de junho, 30 de setembro e 31 de dezembro de cada ano. 
Estão obrigadas à apuração do imposto de renda com base no lucro real as seguintes empresas:

- Receita bruta total, no ano-calendário anterior, seja superior a $\mathrm{R} \$$ 48.000.000,00, ou a $\mathrm{R} \$ 4.000 .000,00$ multiplicado pelo número de meses de atividade do ano-calendário anterior, quando inferior a 12 meses;

- Atividades sejam de bancos comerciais, bancos de investimentos, bancos de desenvolvimento, caixas econômicas, sociedades de crédito, financiamento e investimento, sociedades de crédito imobiliário, sociedades corretoras de títulos, valores mobiliários e câmbio, distribuidora de títulos e valores mobiliários, empresas de arrendamento mercantil, cooperativas de crédito, empresas de seguros privados e de capitalização e entidades de previdência privada aberta;

- Que tiverem lucros, rendimentos ou ganhos de capital oriundos do exterior;

- Que, autorizadas pela legislação tributária, usufruam de benefícios fiscais relativos à isenção ou redução do imposto;

- Que, no decorrer do ano-calendário, tenham efetuado pagamento mensal pelo regime de estimativa (o regime de estimativa é a opção de pagamento mensal, estimado, do Imposto de Renda, para fins de apuração do lucro real em balanço anual).

- Que explorem as atividades de prestação cumulativa e contínua de serviços de assessoria creditícia, mercadológica, gestão de crédito, seleção e riscos, administração de contas a pagar e a receber, compras de direitos creditórios resultantes de vendas mercantis a prazo ou de prestação de serviços (factoring).

O Lucro Presumido é uma forma de tributação simplificada para determinação da base de cálculo do imposto de renda e da Contribuição Social Sobre o Lucro Líquido - CSLL das pessoas jurídicas.

A sistemática é utilizada para presumir o lucro da pessoa jurídica a partir de sua receita bruta e outras receitas sujeitas à tributação. Em termos gerais, trata-se de um lucro fixado a partir de percentuais padrões aplicados sobre a Receita Operacional Bruta - ROB. Sobre o referido resultado somam-se as outras receitas auxiliares (receitas financeiras alugueis esporádicos, entre outras). Assim, por não se tratar do lucro contábil efetivo, mas uma mera aproximação fiscal denomina-se de Lucro Presumido. A

base de cálculo da CSLL corresponde a: $12 \%$ da receita bruta nas atividades comerciais, industriais, serviços hospitalares e de transporte e $32 \%$ para: a) prestação de serviços em geral, exceto a de serviços hospitalares e transporte; b) intermediação de negócios; c) administração, locação ou cessão de bens imóveis, móveis e direitos de qualquer natureza.

O Lucro Arbitramento é uma forma de apuração da base de cálculo do imposto de renda utilizada pela autoridade tributária ou pelo contribuinte, é aplicável pela autoridade tributária quando a pessoa jurídica deixar de cumprir as obrigações acessórias relativas à determinação do lucro real ou presumido, conforme o caso. Por exemplo: quando o contribuinte optante pelo lucro real não tem o livro diário ou razão, quando deixa de escriturar o livro inventário, etc.

Quando conhecida a receita bruta, e, desde que ocorrida qualquer das hipóteses de arbitramento previstas na legislação fiscal, o contribuinte poderá efetuar $\mathrm{o}$ pagamento do imposto de renda correspondente com base nas regras do lucro arbitrado, a partir de 01.01.1995, ocorrida qualquer das hipóteses que ensejam o arbitramento de lucro, previstas na legislação fiscal.

Segundo Pereira (2011), o Brasil tem uma das cargas tributárias mais alta 
do mundo, devido à quantidade de impostos arrecadados, os principais impostos são:

ICMS - Imposto sobre Circulação de Mercadorias

IPI - Imposto sobre Produtos Industrializados

PIS - Programa de Integração Social A alíquota varia entre 0,65\% á 1,65\%

COFINS - Contribuição para Financiamento da Seguridade Social, instituída pela

Lei Complementar 70 de 30/12/1991. A contribuição COFINS, atualmente, é regida pela Lei 9.718/98, com as alterações subsequentes. Sua alíquota varia entre 3\% á 7,6\%

ISS - O Imposto Sobre Serviços de Qualquer Natureza, de competência dos Municípios e do Distrito Federal, tem como fato gerador a prestação de serviços constantes da lista anexa à Lei Complementar 116/2003, ainda que esses não se constituam como atividade preponderante do prestador. O ISS até 31.07.2003 foi regido pelo DL 406/1968 e alterações posteriores. A partir de 01.08.2003, o ISS é regido pela Lei Complementar 116/2003. Sendo que a alíquota mínima é de $2 \%$ e a máxima de 5\% CSLL - A contribuição social sobre o lucro líquido (CSLL ou CSSL) foi instituída pela Lei $\mathrm{n}^{\mathrm{o}} 7.689 / 1988$. Alíquota $12 \%$ da receita bruta nas atividades comerciais, industriais, serviços hospitalares e de transporte; $32 \%$ para a) prestação de serviços em geral, exceto a de serviços hospitalares e transporte; b) intermediação de negócios; c) administração, locação ou cessão de bens imóveis, móveis e direitos de qualquer natureza.

\section{6 - PEQUENAS E MÉDIAS EMPRESAS}

De acordo com Fabretti (2011), tanto para controle de custos, como para apuração do lucro, quanto para determinação de políticas de preços e expansão, a contabilidade é uma ferramenta eficaz para o diagnóstico e acompanhamento das operações das empresas. As pequenas e médias empresas muito podem se beneficiar de tais informações, que competem num mercado sempre ávido por inovações, menores preços e maior eficiência produtiva.

Ainda de discorrendo sobre o tema, Fabretti (2011), as micro e pequenas empresas estão cada vez mais engajadas num processo de crescimento e melhoria contínuos, proporcionando uma concorrência que faz frente às grandes corporações e possibilitando uma nova e qualitativa opção de escolha aos consumidores. Mas, quando colocamos no papel os custos necessários para se manter uma estrutura de grande qualidade e capacidade de atendimento, vemos que, realmente, o que motiva os empreendedores brasileiros vai além do que os livros motivacionais podem explicar, trata-se de mágica, com a obrigatoriedade imposta pela nova regulamentação sobre a Nota Fiscal Eletrônica no país, dezenas de milhares de empreendedores de empresas de pequeno porte passaram a fazer parte desta lista e, adicionar mais um gasto à sua tão cheia lista de dividendos.

Os custos envolvidos na NF-e Fabretti (2011) diz que o Brasil escolheu o momento certo para adaptar o seu sistema de escrituração digital, uma vez que, segundo dados do CETIC, $97 \%$ das empresas brasileiras têm um computador disponível. Porém, o dado estatístico que comprova a quantidade de micro e pequenas empresas com acesso a internet banda larga de qualidade não segue a mesma tendência.

Na percepção de Fabretti (2011), "existem muitos parâmetros para definir as pequenas e médias empresas, muitas vezes dentro de um mesmo país, como no Brasil”. 
Isso mostra que nenhuma definição que se possa ter a respeito de micro e pequenas empresas serão algo absoluto, mas apenas limitado a determinados pontos de vista, ou órgãos aos quais essas definições estão vinculadas, para usufruir os benefícios da Lei Geral imposto aos interessados é que estejam registrados na Junta Comercial ou no Cartório de Títulos e Documentos - Registro Civil de Pessoas Jurídicas, conforme o caso. Não bastasse a exigência focalizada, devem observar os seguintes limites de receita bruta para fins do enquadramento:

Microempresa - ME, quando a pessoa jurídica auferir, ao longo do ano calendário, receita bruta de até $\mathrm{R} \$ 240.000,00$.

Empresa de Pequeno Porte - EPP, nos casos em que a pessoa jurídica auferir em cada ano-calendário, receita bruta situada entre $\mathrm{R} \$ 240.000,00$ e $\mathrm{R} \$ 2.400 .000,00$.

Pequeno Empresário - O legislador do Simples Nacional, ao fazer referência ao pequeno empresário de que tratam os art. 970 e 1.179 da Lei $\mathrm{n}^{\mathbf{o}}$ 10.406/02, estabeleceu aquele tratamento mais diferenciado ainda.

Fabretti (2011) postula que "o empreendedor deve tornar a sua contabilidade uma fonte de informações para que possa tomar decisões seguras e coerentes com seu negócio". Ao utilizar a contabilidade como ferramenta tendo o contador como aliado na gestão da empresa, as possibilidades de continuidade do negocio serão aumentadas e as decisões serão tomadas sob uma nova perspectiva, com muito mais segurança e possibilidades de sucesso.

Nesse aspecto, a contabilidade passa a ocupar a posição de ferramenta de apoio ao empresário, deixa de se prender as normas e regulamentos fiscais para uma posição de apoio gerencial.

Fabretti (2011) explana que o objetivo das demonstrações contábeis de pequenas e médias empresas é oferecer informação sobre a posição financeira (balanço patrimonial), o desempenho (resultado e resultado abrangente) e fluxos de caixa da entidade, que é útil para a tomada de decisão por vasta gama de usuários que não está em posição de exigir relatórios feitos sob medida para atender suas necessidades particulares de informação, podemos evidenciar o valor da contabilidade na gestão de negócios. Tanto para controle de custos, como para apuração do lucro, quanto para determinação de políticas de preços e expansão, a contabilidade é uma ferramenta eficaz para o diagnóstico e acompanhamento das operações das empresas. As pequenas e médias empresas muito podem se beneficiar de tais informações, haja vista que competem num mercado sempre ávido por inovações, menores preços e maior eficiência produtiva.

\section{7 - EMPRESAS DO RAMO ODONTOLÓGICO}

Conforme o Portal da Agência Nacional de Saúde - ANS (2012), as empresas de saúde, inclusive no ramo odontológico tem um órgão regulamentador a ANS

(Agência Nacional de Saúde Suplementar) que fiscaliza todas essas empresas pertencentes a esse ramo de atividade, ou seja, a Agência Nacional de Saúde Suplementar (ANS) é a agência reguladora vinculada ao Ministério da Saúde responsável pelo setor de planos de saúde no Brasil.

De forma simplificada, a regulação pode ser entendida como um conjunto de medidas e ações do Governo que envolve a criação de normas, o controle e a fiscalização de segmentos de mercado explorados por empresas para assegurar o 
interesse público. Ainda segundo a ANS (2012), define uma lista de consultas, exames e tratamentos, denominada Rol de Procedimentos e Eventos em Saúde, que os planos de saúde são obrigados a oferecer, conforme cada tipo de plano de saúde ambulatorial hospitalar com ou sem obstetrícia, referência ou odontológico. Essa lista é válida para os planos contratados a partir de 02 de janeiro de 1999, os chamados planos novos. É válida também para os planos contratados antes dessa data, mas somente para aqueles que foram adaptados à Lei dos Planos de Saúde.

Antes de verificar se você tem direito a um procedimento, não deixe de checar qual o tipo de plano de saúde você tem, ANS (2012) é uma agência reguladora vinculada ao Ministério da Saúde do Brasil que regula o mercado de planos privados de saúde por determinação da Lei n 9.656 de 03 de junho de 1998.

Conforme o Portal da Agência Nacional de Saúde - ANS (2012), autarquia especial federal, foi criada pela Lei $\mathrm{n}^{\circ} 9.961$ de 28 de janeiro de 2000 , sendo responsável em promover a defesa do interesse público na assistência suplementar à saúde, regular as operadoras setoriais, a relação entre prestadoras e consumidores e contribuir para o desenvolvimento das ações de saúde no país, é sediada na cidade do Rio de Janeiro. Sua estrutura é composta por 5 diretorias, cujos responsáveis são escolhidos pelo Poder Executivo Federal para mandatos fixos de 3 anos, com possibilidade de uma recondução de mandato, por mais 3 anos. Esses diretores precisam ser sabatinados pelo Senado Federal.

\section{8 -O SISTEMA PÚBLICO DE ESCRITURAÇÃO DIGITAL (SPED)}

Ao estudar a implantação da Nota Fiscal eletrônica, não se pode deixar de mencionar o Sped Contábil, que é uma forma de escrituração digital.

Bresk (2011) diz que a maioria dos contribuintes já se utiliza dos recursos de informática para efetuar tanto a escrituração fiscal como a contábil, as imagens em papel simplesmente reproduzem as informações oriundas do meio eletrônico. A facilidade de acesso à escrituração, ainda que não disponível em tempo real, amplia as possibilidades de seleção de contribuintes e, quando da realização de auditorias, gera expressiva redução no tempo de sua execução.

O Sped é instrumento que unifica as atividades de recepção, validação, armazenamento e autenticação de livros e documentos que integram a escrituração comercial e fiscal dos empresários e das sociedades empresárias, mediante fluxo único, computadorizado, de informações.

Conforme a Secretaria da Receita Federal do Estado de São Paulo (2012), o Sped Contábil visa à substituição da emissão de livros contábeis (Diário e Razão) em papel pela sua existência apenas digital. Os livros Diários e Razão serão gerados a partir de um mesmo conjunto de informações digitais. O Sped Contábil está sendo construído um programa para validação e transmissão do arquivo com a escrituração contábil. Esse aplicativo também exibirá na tela a contabilidade da empresa, nos formatos de diário ou razão, e as Segundo Bresk (2011), as Demonstrações Contábeis. O arquivo deverá ser assinado digitalmente pelo empresário ou representante legal da sociedade empresária e pelo contabilista responsável pela escrituração.

O aplicativo conterá, também, funcionalidades para a realização das assinaturas digitais. Depois de assinado, o arquivo será encaminhado para o Sped que disponibilizará para as Juntas Comerciais as informações necessárias à autenticação. A 
Junta Comercial fará uma série de validações próprias e depois autenticará o livro entregue. Essa informação de autenticação é fornecida ao titular da escrituração por intermédio do Sped por meio de consulta à Internet.

Conforme Bresk (2011), o Sistema Público de Escrituração Digital (SPED) é um projeto que foi instituído em 2007 pelo Ministério da Fazenda e faz parte do Programa de Aceleração do Crescimento do Governo Federal (PAC 2007 - 2010), constituindo-se em mais um avanço nas relações entre o fisco e os contribuintes. O projeto consiste na modernização da sistemática atual de cumprimento das obrigações acessórias dos contribuintes, utilizando-se da certificação digital dos documentos, garantindo assim a validade jurídica dos mesmos. O projeto é composto de três grandes subprojetos: Escrituração Contábil Digital, Escrituração Fiscal Digital e NF-e - Ambiente Nacional.

É a substituição da escrituração em papel pela Escrituração Contábil Digital - ECD, também chamada de SPED-Contábil. Trata-se da obrigação de transmitir em versão digital os seguintes livros: livro Diário, livro Razão e seus auxiliares, Balancetes Diários, Balanços e fichas de lançamento comprobatórias dos assentamentos neles transcritos.

Assinala Bresk (2011) que, o SPED é uma iniciativa das administrações tributárias das três esferas de governo em parceria com outras instituições, com a finalidade de estabelecer um novo tipo de relacionamento entre governo e sociedade, baseado na transparência mútua, com reflexos positivos para toda a nação brasileira.

Dentre os objetivos apontados no projeto, pode-se destacar, entre outros:

a) Promover a integração dos fiscos, mediante a padronização e compartilhamentodas informações contábeis e fiscais, respeitadas às restrições legais.

b) Racionalizar e uniformizar as obrigações acessórias para os contribuintes, com estabelecimento de transmissão única de distintas obrigações acessórias de diferentes órgãos fiscalizadores.

c) Tornar mais célere a identificação de ilícitos tributários, com a melhoria do controle dos processos, a rapidez no acesso as informações e a fiscalização mais efetiva das operações com o cruzamento de dados e auditoria eletrônica.

A Secretaria da Receita Federal do Estado de São Paulo (2011) esclarece que, antes de ser um simples instrumento de aumento de arrecadação, o SPED pretende proporcionar melhor ambiente de negócio para o país e a redução do "custo Brasil", tendo ainda a missão de modernizar os processos de interação entre a administração pública e as empresas em geral.

\section{9 - IMPACTOS E BENEFÍCIOS DA NOTA FISCAL ELETRÔNICA - NF-E}

Ressalta o Portal da Prefeitura do Estado de São Paulo (2011),que pioneiramente o Município de São Paulo instituiu que cada prestação de serviço transacionada com a NF-e acumulará créditos que poderão ser utilizados para abater até $50 \%$ do IPTU - Imposto sobre Propriedade Territorial Urbana, devido por pessoas físicas ou jurídicas.

Oportuno verificar-se que a modernidade e a velocidade desses novos controles resultarão numa maior arrecadação, com o crescimento do volume de tributos arrecadados, impulsionado principalmente pela regulamentação de novas empresas, o que poderá sinalizar uma vaga esperança para a redução da carga tributária. 
Conforme Portal da Prefeitura do Estado de São Paulo (2011) e o Portal da Secretaria da Receita Federal do estado de São Paulo, que o projeto NF-e instituirá

mudanças significativas no processo de emissão e gestão das informações fiscais, trazendo grandes benefícios para os contribuintes, para a sociedade e para as administrações tributárias:

a) Benefícios para o Contribuinte Vendedor (Emissor da NF-e)

- Redução de custos de impressão;

- Redução de custos de aquisição de papel;

- Redução de custos de envio do documento fiscal;

- Redução de custos de armazenagem de documentos fiscais;

- Redução de tempo de parada de caminhões em Postos Fiscais de Fronteira;

b) Benefícios para o Contribuinte Comprador (Receptor da NF-e)

- Eliminação de digitação de notas fiscais na recepção de mercadorias;

- Planejamento de logística de entrega pela recepção antecipada da informação F-e;

- Redução de erros de escrituração devido a erros de digitação de Notas Fiscais;

- Simplificação de obrigações acessórias, como dispensa de Autorização para

Impressão de Documentos Fiscais - AIDF;

- Incentivo a uso de relacionamentos eletrônicos com clientes;

- Incentivo a uso de relacionamentos eletrônicos com fornecedores;

c) Benefícios para a Sociedade

- Redução do consumo de papel, com impacto em termos ecológicos;

- Incentivo ao comércio eletrônico e ao uso de novas tecnologias;

- Padronização dos relacionamentos eletrônicos entre empresas;

- Surgimento de oportunidades de negócios e empregos na prestação de serviços

ligados a Nota Fiscal Eletrônica.

d) Benefícios para as Administrações Tributárias

- Aumento na confiabilidade da Nota Fiscal;

- Melhoria no processo de controle fiscal, possibilitando um melhor intercâmbio e compartilhamento de informações entre os fiscos;

- Redução de custos no processo de controle das notas fiscais capturadas pela fiscalização de mercadorias em trânsito;

- Diminuição da sonegação e aumento da arrecadação;

- Suporte aos projetos de escrituração eletrônica contábil e fiscal da Secretaria da Receita Federal do Estado de São Paulo, (Sistema Público de Escrituração Digital SPED).

Esclarece Fabretti (2011), que as pequenas e médias empresas já começam a sentir os benefícios da emissão da nota fiscal eletrônica. Os custos com impressão de talões e o tempo despendido para o preenchimento são minimizados com a digitalização do processo, no entanto, o que mais surpreendeu os empresários foi o maior controle sobre as vendas, impostos a pagar e, principalmente, redução de erros.

De acordo com Fabretti (2011) levantamento feito pela Receita Federal do estado de São Paulo, junto a empresas de pequeno e médio porte que já utilizam a NFE, 64\% afirmam que a principal vantagem da adoção do sistema está no maior controle das vendas e dos impostos a pagar. Outros $28 \%$ disseram que o processo ficou mais ágil, enquanto $8 \%$ não sentiram diferença alguma. 
Do ponto de vista contábil de Fabretti (2011), o processo ficou muito mais prático, pois a possibilidade de escrituração eletrônica e automática dos livros fiscais e redução do custo da mão-de-obra facilita muito a vida dos pequenos.

\section{3 - METODOLOGIA}

O presente estudo utilizou pesquisa bibliográfica e sites oficiais para a fundamentação teórica e questionário aplicado como um instrumento de coleta de dados. Para tal, considerou-se empresas pesquisadas de três ramos de atividades diferentes - uma do ramo de atividade de assistência odontológica, uma do ramo de industrial de alimentos e uma do ramo de prestação de serviços contábeis.

A pesquisa inserida neste artigo, traz uma avaliação das empresas em relação a esse novo sistema de emissão de Notas Fiscais Eletrônica em relação ao método antigo.

As entrevistas tiveram o objetivo de identificar alguns indicadores para medir as variáveis pesquisadas na fase quantitativa e obter subsídios para a elaboração dos quadros, com os atributos considerados mais relevantes abordados nesse artigo.

O questionário foi direcionado a profissionais com cargo mínimo de coordenaçãa das empresas pesquisadas, as perguntas do questionário estão indicadas no Quadro 1:

\section{Perguntas}

1 Você ficou satisfeito com o novo processo de emissão da NF-e?

2 Quanto ao sistema disponibilizado pela SEFAZ-SP, supre as necessidades da sua empresa?

3 O preenchimento da Nota Fiscal Eletrônica ficou mais rápido?

$4 \quad$ Sua empresa já se adaptou com a nova forma de escrituração digital Sped?

$5 \quad$ Você acha que o Sistema Tributário no Brasil deve passar por alterações?

6 Sua empresa possui algum tipo de Sistema Integrado, se sim ele já está adaptado para entrega do Sped?

7 Você acha que com a NF-e e Sped Contábil sua empresa vai ter um ganho no fluxo de documentos?

\section{4 - ANÁLISE DE DADOS}

A análise de dados baseia-se em questionário enviado a uma empresa do ramo Comercial, Prestação de Serviços Contábeis e Indústria de Alimento.

Diante das respostas de aprovado e reprovado, indicado pela empresa do ramo de Alimentos, ao responder o questionário, atentou-se que em relação ao Sped contábil, houve uma reprovação na questão das dificuldades de importação do arquivo no programa disponibilizado pela Receita Federal, pois a importação gera muitos arquivos de erros até a sua transmissão final, gerando uma incerteza de que o arquivo foi transmitido corretamente, sobre a conclusão de aprovação, a empresa identificou que nos 03 primeiros meses usando esse novo sistema de emissão da NF-e, a empresa obteve uma redução de $12 \%$ no custo com impressão, correios, conforme Portal da Prefeitura do Estado de São Paulo (2011) que indica alguns dos benefícios que os contribuintes irão ter com esse novo processo. 


\section{Causa Influente Conclusão}

$\begin{aligned} 1 & \text { Satisfação do contribuinte com o novo processo de emissão da NF-e } \\ \text { Aprovado } & \text { Satisfação do contribuinte em relação ao sistema disponibilizado pela }\end{aligned}$ SEFAZ-SP Reprovado

3 Rapidez no preenchimento da Nota Fiscal Eletrônica Reprovado Sped Reprovada

4 Os contribuintes já se adaptaram com a nova forma de escrituração digital Aprovado

5 Alteração no Sistema Tributário no Brasil Reprovado 7 Sistema Integrado

68 Vantagens e desvantagens Sped Aprovado

Das respostas que a empresa do ramo de serviços contábeis proporcionou, destaca-se a de que a mesma aprovou o novo sistema de escrituração contábil (SPED) e com isso obteve um ganho de produtividade em relação a alguns funcionários que antes fazia a escrituração nos livros fiscais. Isso nos leva a refletir que as empresas que utilizam o Sped têm a vantagem de unificar as atividades de recepção, validação, armazenamento e autenticação de livros e documentos que integram a escrituração comercial e fiscal dos empresários e das sociedades empresárias, mediante fluxo único, computadorizado, de informações e, assim geram ganhos significativos.

\section{Causa Influente Conclusão}

1 Satisfação do contribuinte com o novo processo de emissão da NF-e Aprovado

2 Satisfação do contribuinte em relação ao sistema disponibilizado pela SEFAZ-

SP Reprovado

3 Rapidez no preenchimento da Nota Fiscal Eletrônica Aprovado

4 Os contribuintes já se adaptaram com a nova forma de escrituração digital

Sped Reprovada

5 Alteração no Sistema Tributário no Brasil

Reprovado 7 Sistema Integrado Aprovado

8 Vantagens e desvantagens Sped Aprovado

Quadro 3 - Satisfação e aprovação respondida pela empresa do Ramo Serviços

Contábeis. Fonte: Empresa pesquisada (2010)

Dentre as respostas que a empresa no ramo de odontológico indicou, pode-se verificar que a mesma reprovou o sistema em relação à lentidão do site e que o mesmo deveria passar por uma reformulação para atender a real necessidade do contribuinte.

\section{Causa Influente Conclusão}

1 Satisfação do contribuinte com o novo processo de emissão da NF-e Aprovado

2 Satisfação do contribuinte em relação ao sistema disponibilizado pela SEFAZSP Reprovado

3 Rapidez no preenchimento da Nota Fiscal Eletrônica Aprovado

4 Os contribuintes já se adaptaram com a nova forma de escrituração digital Sped Reprovada

5 Alteração no Sistema Tributário no Brasil 
Reprovado 7 Sistema Integrado Aprovado

8 Vantagens e desvantagens Sped Aprovado

Ao analisar as conclusões das três empresas, simultaneamente, sobre a conclusão aprovada ou reprovada, pode-se verificar que as perguntas 1,7 e 8 receberam respostas como aprovado o que pode indicar que as empresas adquiriram redução do Custo de confecção de novos talonários (em papel), e do custo de armazenamento dos documentos fiscais, envolvimento com algum tipo de sistema integrado, pois facilita na integração empresa $x$ Escrituração Digital e assim diminui ainda mais a digitação; e, por fim as empresas pesquisadas mesmo com pouco entendimento do processo, têm a convicção de que esse sistema de escrituração facilitar muito, devido a pouca circulação, armazenamento de papeis, livros.

Sobre a conclusão reprovada pode-se verificar que as perguntas 2, 4 e 5 tiveram a mesma resposta o que nos induz a pensar que todas as empresas indicam a lentidão do sistema como ponto importante do processo; que não se adaptaram ao novo método de escrituração devido pouco entendimento do processo; e, que acham o sistema tributário no Brasil é umas das mais altas do mundo, por conta disso, deveria haver uma reformulação dos tributos e com isso o pagamento de menos imposto possibilitando sobra de dinheiro para investimento nas empresas e proporcionar crescimento.

\section{5 - CONSIDERAÇÕES FINAIS}

Esse processo de emissão da Nota Fiscal Eletrônica para o para os órgãos competentes é importante têm o objetivo de racionalizar e modernizar a administração tributária brasileira, reduzindo custos e entraves burocráticos, facilitando o cumprimento das obrigações tributárias e o pagamento de impostos e contribuições, além de fortalecer o controle e a fiscalização por meio de intercâmbio de informações entre as administrações tributárias. Mas para o lado do contribuinte esse processo tem de haver mudanças principalmente no processo eletrônico de emissão pois ainda está um processo lento e moroso. Num modo geral todos ganham com essa modernização, pois se espera um controle eficaz nas empresas que sonegam impostos.

\section{REFERÊNCIAS}

Agência Nacional da Saúde ANS - disponível em http://www.ans.gov.br/index.php/materiais-para-pesquisas/perfil-do-setor/legislacao acessado 01/02/2012.

BECKER, Alfredo Augusto. Teoria Geral do Direito Tributário, $5^{\circ}$ ed. São Paulo : Noeses, 2007. 728p.

BRESK, Lucia Helena. Sped: Sistema Público de Escrituração Digital, $1^{\text { }}$ ed. São Paulo. Juruá 2009.

BORGES, Humberto Bonavides. Manual de Procedimentos Tributários - IPI, ICMS ISS: Guia Prático do Gerente, Consultor e Analista Tributário das Empresas. $3^{\circ}$ 
Ed.São Paulo : Atlas, 2009.

FABRETTI, Láudio Camargo. Práticas Tributária das Micros, Pequenas e Médias Empresas, $7^{\circ}$ ed. São Paulo. Atlas 2011.

PEREIRA, Luiz Alberto As Taxas no Sistema Tributário Brasileiro. $3^{\circ}$ ed. São Paulo, Jurua.2011

Prefeitura do Estado de são Paulo-disponível em http://nfpaulistana.prefeitura.sp.gov.br/informacoes, acesso em 20/01/2011 Secretaria da Receita Federal - - disponível em

BRASIL - MINISTÉRIO DA FAZENDA. Disponível em: https://www.fazenda.sp.gov.bracessado em 09/01/2012 